\title{
Estimation of source parameters of local earthquakes based on inversion of waveform data
}

\author{
Prosanta K. Khan ${ }^{1, *}$, Kuntal Bhukta ${ }^{2}$ and Prantik Mandal ${ }^{3}$ \\ ${ }^{1}$ Department of Applied Geophysics, Indian Institute of Technology (Indian School of Mines), Dhanbad 826 004, India \\ ${ }^{2}$ Geological Survey of India, Khanij Bhavan, GSI Complex, 15-16 Jhalana Dungri, Jaipur 302 004, India \\ ${ }^{3}$ National Geophysical Research Institute, Uppal Road, Hyderabad 500 007, India
}

Generalized inversion has been used to estimate the various source parameters using $S$-wave spectra of 17 local crustal earthquakes recorded at the Dhanbad broadband seismic station, Jharkhand, India. Source parameters of another nine local events were compiled from an earlier study for detailed analysis. It was found from the source parameters of 26 events, that the corner frequency lies between 4.56 and $8.62 \mathrm{~Hz}$, seismic moment between $6.2 \mathrm{E}+12$ and $2.11 \mathrm{E}+16 \mathrm{~N}-\mathrm{m}$, stress drop between 0.11 and $37.13 \mathrm{MPa}$, source radius between 144 and $291 \mathrm{~m}$, source displacement between 0.24 and $229 \mathrm{~cm}$, moment magnitude between 2.44 and 4.82, and seismic energy between $8.3 E+06$ and $1.13 E+13$ Joule. Various empirical relationships were established based on the results of these 26 events, and it was found that the stress drop, corner frequency, source radius and source displacement are inter-related. Analysis also showed that the source parameters were correlated for stress-drop intervals of $\Delta \sigma>3.0 \mathrm{MPa}$ and $\Delta \sigma<3.0 \mathrm{MPa}$, and were interpreted to be caused by interrupted rupture propagation because of strain weakening of the rock masses. The mere correlation between focal depth and stress drop found in the present study apparently accounts for high heterogeneities present in the crust beneath the study area.

Keywords: Generalized inversion, local earthquakes, source parameters, waveform data.

THE study area in Dhanbad, Jharkhand, India (Figure 1) lies between latitudes $22.5^{\circ}$ and $25.5^{\circ} \mathrm{N}$, and longitudes $85^{\circ}$ and $88.3^{\circ} \mathrm{E}$, and was affected by the great earthquakes of 1833 $\left(M_{\mathrm{w}} 7.6\right), 1934\left(M_{\mathrm{w}} 8.1\right), 1988\left(M_{\mathrm{w}} 6.8\right), 2011\left(M_{\mathrm{w}} 6.9\right)$, and the recent $2015\left(M_{\mathrm{w}} 7.8\right)$ Nepal earthquake ${ }^{1,2}$. The region also experienced several earthquakes, namely 1868 Manbhum (M 5.7), 1868 Hazaribagh (M 5.0), 1958 Bihar, 1963 Ranchi ( $M$ 5.0), and 1969 Bankura ( $M$ 5.7 $)^{3,4}$. Besides, the study area is tectonically important, connecting three important tectonic domains, namely the Shillong Plateau, the Eastern Himalaya and the Indo-Myanmar Ranges.

\footnotetext{
*For correspondence. (e-mail: khanprosanta1966@iitism.ac.in)
}

A realistic assessment of shallow-level crustal behaviour vis-à-vis earthquake vulnerability of an intraplate region can be understood through different lines of evidence and their mutual interrelationships. In this backdrop, several models were proposed to account for the intraplate moderate-to-large earthquakes ${ }^{5-9}$. Differential crustal movement, stress amplification near plutons or regional gravity lows, lithospheric flexure, localized strain, intersecting faults and fluid flow in the old rift are normally considered responsible for these earthquakes. The ground accelerations for large intraplate earthquakes can be predicted using data of smaller shocks, and thereby, the stress drop, corner frequency and $f_{\max }$ (maximum corner frequency) have applications in the estimation of strong ground motions. The source parameters are thus useful to design source scaling of an earthquake and understanding the seismotectonics of a region ${ }^{10,11}$. With the availability of quality digital seismic records, the source parameters as well as scaling relationships between earthquake size, fault dimensions, stress drop, etc. for small-magnitude earthquakes are now routinely examined. Spatial and temporal variations of stress drop can also be useful in earthquake prediction research ${ }^{12,13}$.

The present study aims at understanding the seismic behaviour of parts of the Eastern Indian Shield based on estimated source parameters and scaling relationships. The Brune ${ }^{14}$ model was used to estimate the source parameters of 17 local crustal earthquakes. The hypocentral parameters of these earthquakes were taken from the catalogue of the India Meteorological Department (IMD), New Delhi. IMD was the nodal agency of the Government of India (GoI) for monitoring seismicity in and around the country till 2014. The National Centre for Seismology (NCS), an attached office of the Ministry of Earth Sciences, GoI, was set up in 2014, and the relevant responsibility and related matters were handed over to this national nodal agency. IMD was reporting hypocentral solutions of all the detected earthquakes with an expected accuracy of $\pm 2 \mathrm{~km}$ in epicentre and $\pm 5 \mathrm{~km}$ in focal depth for the outer boundary of the leading network $^{15}$. During early 2020, five seismological observatories were active in the present study area, and three 


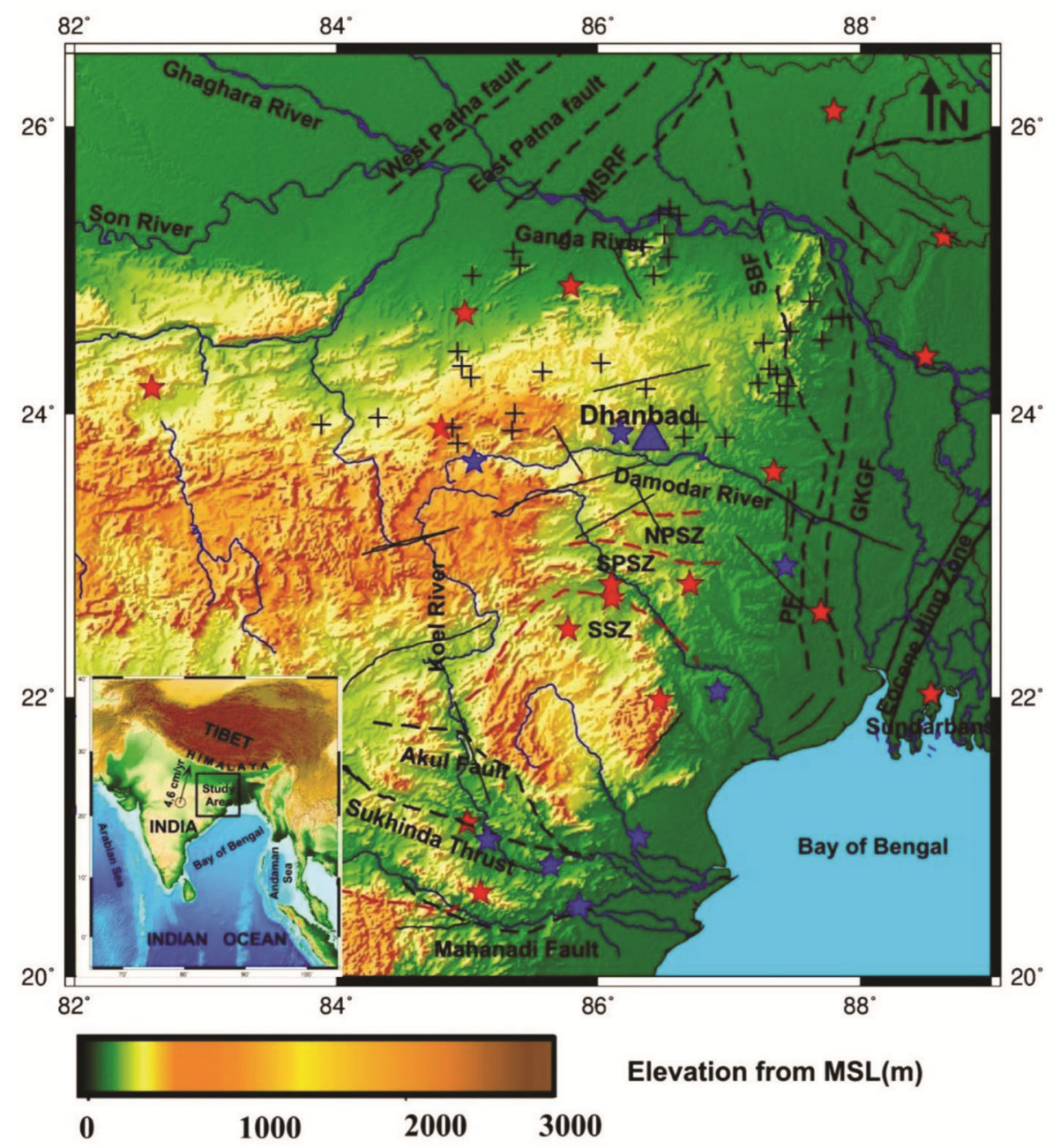

Figure 1. Map showing the tectonic set-up of the central part of the Eastern Indian Shield region ${ }^{57}$. Red solid stars represent the epicentres of 17 earthquakes. Blue solid stars represent the epicentres of nine earthquakes, compiled from Biswas and Mandal ${ }^{17}$. Plus symbols represent the locations of hot springs. Blue solid triangle represents the location of IIT(ISM) digital broadband station (DHN). SSZ, Singhbhum Shear Zone; SPSZ, South Purulia Shear Zone; NPSZ, North Purulia Shear Zone; GKGF, GarhmaynaKhandaghosh Fault; SBF, Sainthia Bahmani Fault; MKF, Malda-Kishanganj Fault; RPSZ, Ranipather Shear Zone; MSRF, Munger-Shasarsa Ridge Fault; PF, Pingla Fault.

stations were further added for improving the recording of local earthquakes (figure 8 of Srivastav et $a l^{15}$ ). Strengthening of the seismological network was continued, and accelerated further in 2011 with the inclusion of more digital broadband seismic stations, which has improved the recording and accuracy of hypocentral parameters of both local and regional earthquakes ${ }^{16}$. Now, 9-10 broadband stations are operating in and around the Eastern Indian Shield (figure 3 of Prakash et $\left.a l .{ }^{16}\right)$. All the 17 earthquakes analysed in the present study are apparently found within the distribution of these recording stations, and thus the network configuration has further reduced the errors of hypocentral parameters.

The Brune ${ }^{14}$ model describes near and far-field displacement time functions and includes the effect of fractional stress drop. We are running a digital broadband seismic station in the premises of Indian Institute of
Technology (Indian School of Mines; IIT (ISM)), Dhanbad since December 2006. Hundreds of local earthquakes have been recorded at this station during the last decade and more. The waveform data of 17 events with high signal-to-noise ratio and distinct $P$-phases were considered for computation of source parameters (Table 1). We have compiled and added source parameters of another nine local events ${ }^{17}$ for developing the empirical relationships between these parameters (Table 1). This process has enhanced the number of data as well as the reliability of empirical relationships. The epicentral distances of these events lie between 95 and $390 \mathrm{~km}$, and the magnitude $\left(M_{\mathrm{w}}\right)$ ranges from 2.91 to 4.82 . Source parameters of ten small-magnitude, local earthquake events, recorded by a temporary network during 2013-14, were computed by Biswas and Mandal $^{17}$. These earthquakes of magnitude $\left(M_{\mathrm{w}}\right)$ 2.44-3.57 occurred mainly in the southern part 
RESEARCH ARTICLES

Table 1. Hypocentral and source parameters of 26 local events. The parameters of first 17 events (serial nos 1-17) were computed under the present study and parameters of the remaining nine events (serial nos 18-26) were taken from Biswas and Mandal ${ }^{17}$

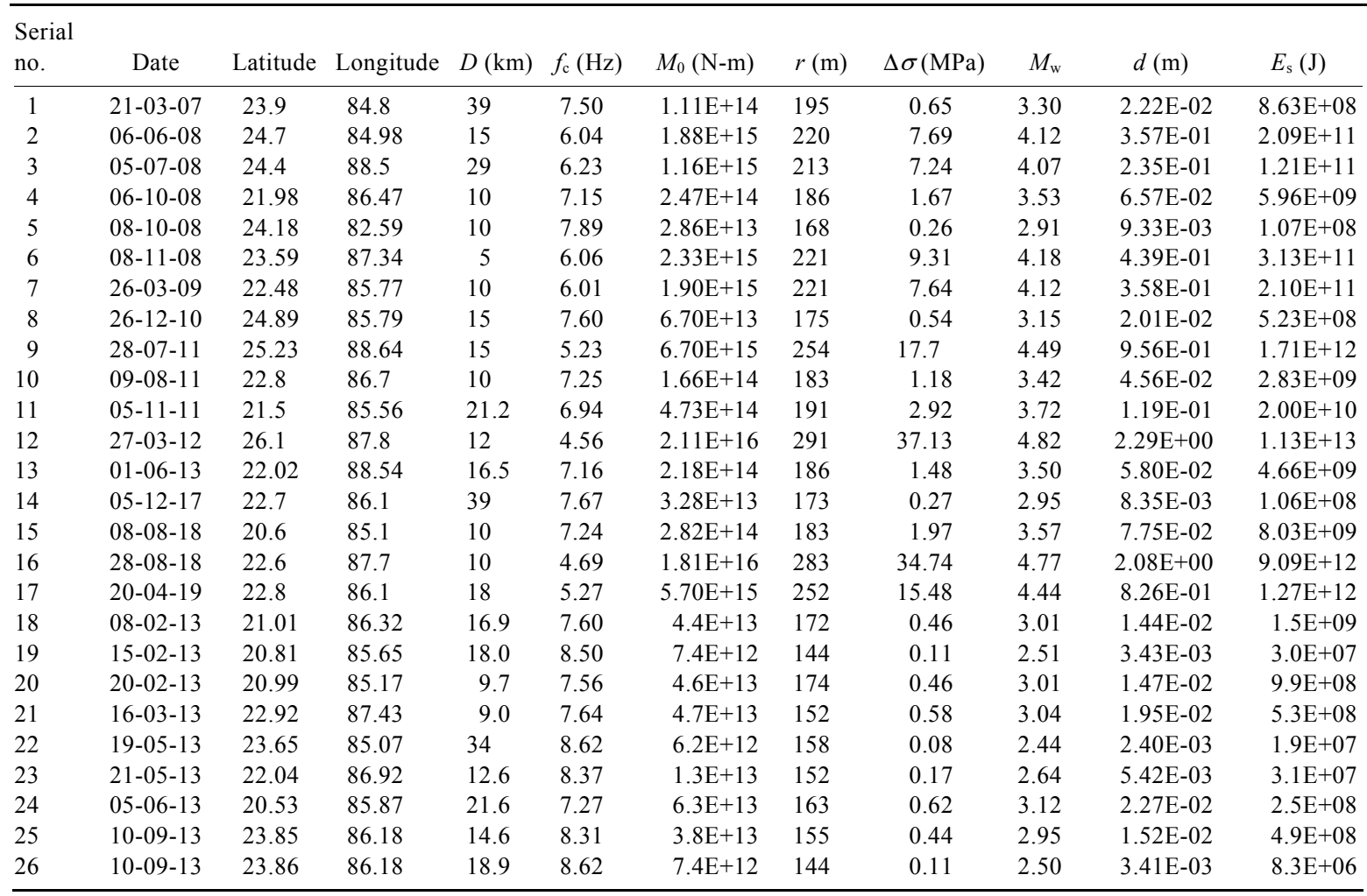

$D$, Focal depth; $f_{\mathrm{c}}$, Corner frequency; $M_{0}$, Seismic moment; $r$, Source radius; $\Delta \sigma$, Stress drop; $M_{\mathrm{w}}$, Moment magnitude; $E_{\mathrm{s}}$, Seismic energy release; $d$, Source displacement.

(south of $24^{\circ} \mathrm{N}$ ) of the present study area. This study has considered events during 2007-19, and eight events have magnitude of $>4.0$. The inclusion of six events, which occurred beyond $24^{\circ} \mathrm{N}$, has increased the areal extension of the region, and the results of the present study can be used for hazard analysis in a wider zone of high population density.

\section{Tectonic setting of the Eastern Indian Shield}

The Eastern Indian Shield, covering parts of south Bihar, north Odisha, southwestern part of West Bengal, and Jharkhand, consists of several ovoid granitoid bodies of variable dimensions along with their enclaves and supracrustal envelopes ${ }^{18}$. The area was evolved through successive cycles of interactions of microplates with intervening periods of quiescence ${ }^{19}$. The area is predominantly composed of a mosaic of several geological provinces having distinct tectonic-magmatic signatures, and regionally bounded by the Himalayan Frontal Thrust in the north and Singhbhum craton in the south ${ }^{19}$. Vast Gangetic alluvium and the Quaternary sediments of the Bengal Basin border its eastern part, whereas the western part is demarcated by the Mahanadi Gondwana sediments and a part of the Chhotanagpur Plateau (Figure 1). The
Rajmahal Traps of Upper Jurassic to Lower Cretaceous occupy the contact zone of the Chhotanagpur Gneiss Complex and the Bengal Basin. The Indian plate is subducting both towards east and north (Figure 1), and the northern margin is transformed to a diffused Himalayan plate boundary, which is known to be one of the most seismically active parts of the world ${ }^{1,20,21}$. The compressive stress fields arise due to back-propagated strain energy released by continued penetration of the Indian plate beneath the Himalaya. These processes initiated deformation in the study area as well as along the eastern subduction margin of India ${ }^{22}$. The transmitted compression is well-extended up to the Central Indian Basin in the Indian Ocean ${ }^{23,24}$.

One of the oldest Achaean cratonic nuclei of the Indian Peninsula is reported from this terrain, and is represented by the composite batholithic complex of the Singhbhum. The area passed through Archaean subduction dynamics, rifting, mantle plume tectonics, and mafic magmatism ${ }^{25,26}$ because of the interaction of the converging Singhbhum and Chhotanagpur microplates during the Precambrian ${ }^{19}$. The intervening quiescence in the three successive cycles of plate motion allowed isostatic adjustments through uplifting, intrusions of basic dyke swarms, erosion and paralic sedimentation ${ }^{18}$. Mafic and ultramafic emplacements occurred within deep fractures south of the 
21-03-2007 16:34:36

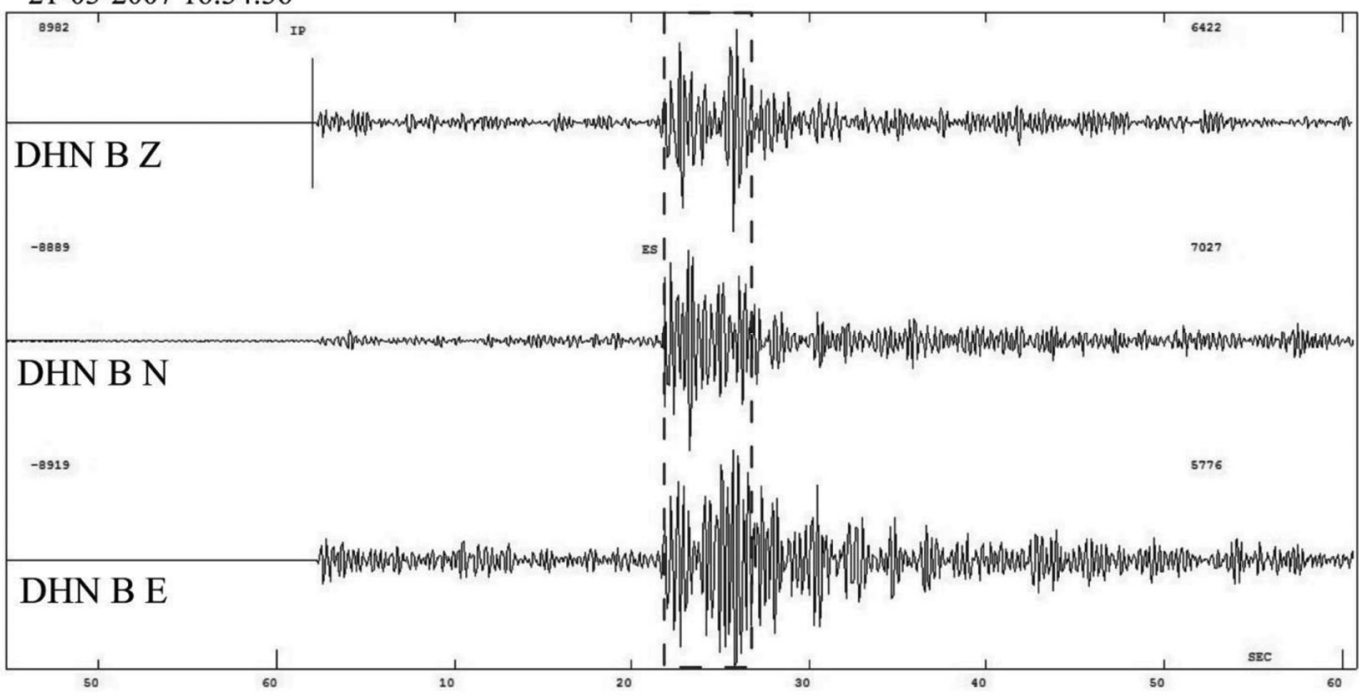

Figure 2. Three-components response of the broadband digital seismometer for a local earthquake recorded at Dhanbad station. The zooming option of $S$-wave was used for the estimation of source parameters, as explained in Figure 3.

Chhotanagpur area. The compressional stress generated by the plate convergence caused $\mathrm{N}-\mathrm{S}$ crustal shortening, and resulted in the upliftment of the Chhotanagpur granite-gneiss terrain with coeval reactivation and fresh fracture formation in the basement of the Chhotanagpur tectonic domain ${ }^{27}$. The region consists of numerous landforms, viz. plateau, hills, uplands, plains and major regional lineaments, namely the Ganga and Damodar rivers. The South and North Purulia Shear Zones and the Singhbhum Shear Zone pass through south of the area. Dhanbad district lies in the mid-eastern part of the Chhotanagpur microplate having a basement of granitegneissic complex and a drainage system of part of the Damodar Gondwana Basin.

\section{Methodology}

A two-stage technique was followed to compute source parameters of the 17 local crustal earthquakes (Table 1). Displacement of $S$-wave spectra was computed first using SAC (Seismic Analysis Code) from the horizontal components of the three-component digital record (Figure 2). Instrumental correction was applied on each component by deconvolving the instrumental response of the seismograph station, and events of moment magnitude $\left(M_{\mathrm{w}}\right)$ more than 2.9 with waveform of signal-to-noise ratio $(S / N) 2.0$ and above were considered for the LevenbergMarquardt inverse modelling. The Levenberg-Marquardt algorithm takes advantages of the Gauss-Newton and steepest descent method, which facilitates rapid convergence of the solution. Initial guessed values of corner frequency and low-frequency spectral level were selected from the respective spectra, and the inverted spectra were calculated using the $\chi^{2}$ source spectral model. The nor- malized difference between the inverted and observed spectra was considered until the difference converged to a minimum value. This gives a better visual fit between the observed and inverted displacement spectra and provides the best model parameters, i.e. corner frequency and long-period spectral level (Figure 3). We further calculated the source parameters such as source radius, static stress drop, seismic moment and moment magnitude using these computed model parameters.

\section{Inversion procedure}

Spectral amplitude of the earthquake signal was attenuated because of an elasticity of the medium. The reduced spectral amplitudes $(A(f, R))$ at a distance $R$ from the earthquake source can be expressed as

$$
A(f, R)=\left(\frac{A_{0}}{R^{-\gamma}}\right) \mathrm{e}^{\pi R f / Q_{0} V_{S}},
$$

where $A_{0}$ is the spectral amplitude at the source, $Q_{0}$ the dimensionless $S$-wave quality factor at frequency $1 \mathrm{~Hz}, f$ the frequency, $\gamma$ the geometrical spreading and $V_{\mathrm{S}}$ is the $S$-wave velocity. A frequency-independent $Q_{0}$ is assumed for best fitting in the datase ${ }^{28,29}$.

The linearized form of eq. (1) assuming $\gamma=1$ is as follows ${ }^{29}$

$$
\ln \{A(f, R)\}=\ln A_{0}-\ln R-\frac{\omega t^{*}}{z},
$$

where

$$
t^{*}=\frac{R}{Q_{0} V_{0}} \text { and } \omega=2 \pi f .
$$

CURRENT SCIENCE, VOL. 119, NO. 7, 10 OCTOBER 2020 

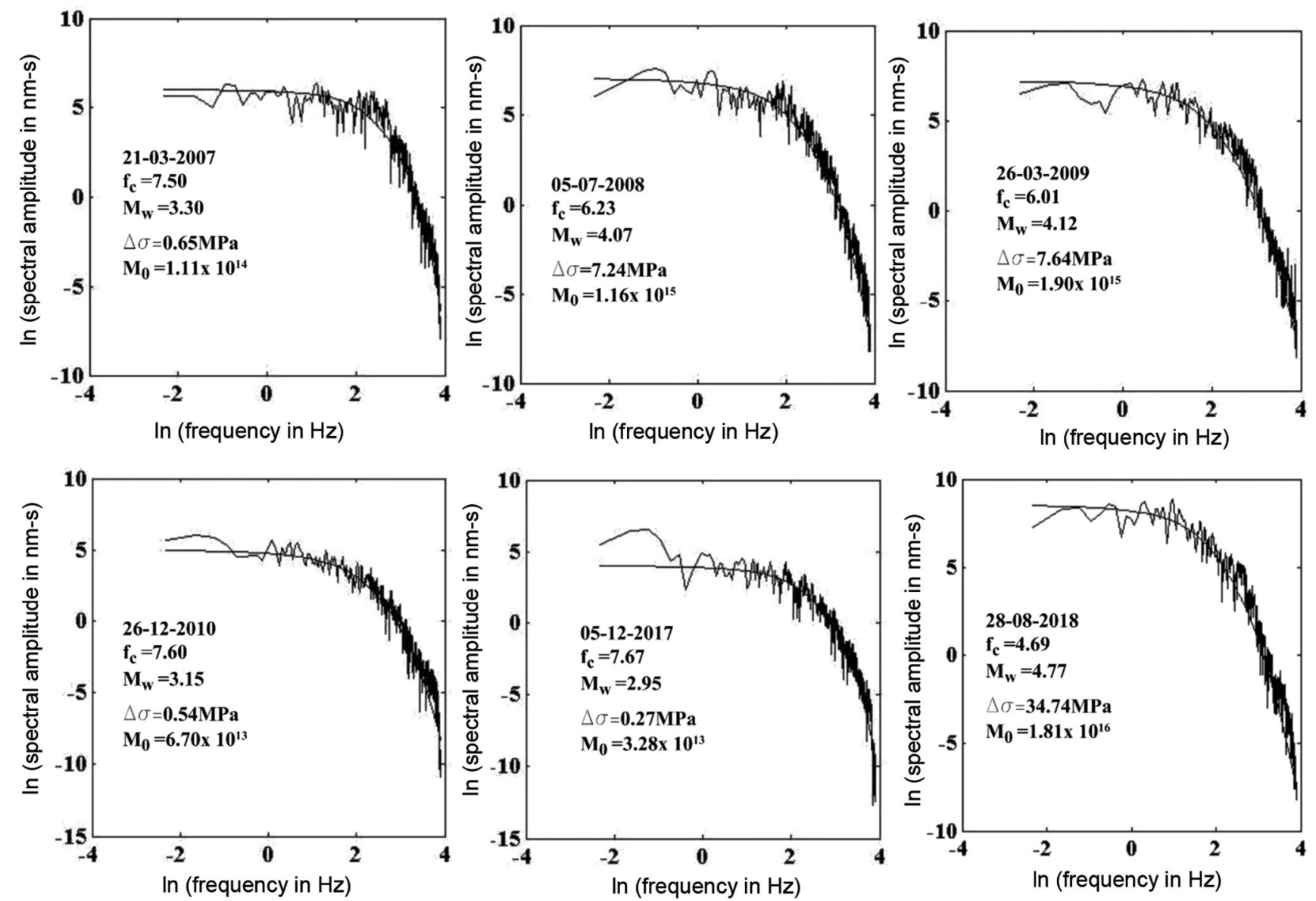

Figure 3. Spectrum analysis for the estimation of low-frequency spectral level $\left(\Omega_{0}\right)$ and corner frequency $\left(f_{\mathrm{c}}\right)$. Other parameters such as moment magnitude $\left(M_{\mathrm{w}}\right)$, source radius $(r)$, stress drop $(\Delta \sigma)$, and seismic moment $\left(M_{0}\right)$ were estimated using $\Pi_{0}$ and $f_{\mathrm{c}}$.

The source term $A_{0}$ for $S$-waves under high frequency fall-off can be written as ${ }^{28}$

$$
A_{0}=\frac{\Pi_{0}}{\left\{\left(1+\frac{f}{f_{\mathrm{c}}}\right)^{4}\right\}^{1 / 2}} .
$$

From eqs (2) and (3), taking $t^{*}=0$ yields

$$
\begin{aligned}
& \ln \{A(f, R)\}=\ln \left[\frac{\Pi_{0}}{\left\{\left(1+\frac{f}{f_{\mathrm{c}}}\right)^{4}\right\}^{1 / 2}}\right]-\ln R \\
& =\ln \left[\frac{\Pi_{0}}{B_{4}^{1 / 2}}\right],
\end{aligned}
$$

where $B_{4}=\left(1+f / f_{c}\right)^{4}$.

The $R$ term is dropped because the formula for moment is corrected from the geometrical spreading effect.
The $B_{4}$ term is expanded in a Taylor series for finding the roots of nonlinear equations $s^{30}$, and the final equation is reduced to

$$
\ln (A(f . R))=\ln \Pi_{0}-0.5 \ln B_{4}+2 B_{4}^{-1}\left(\frac{f}{f_{\mathrm{c}}}\right)^{4}\left(\frac{\Delta f_{\mathrm{c}}}{f_{\mathrm{c}}}\right) .
$$

The least-squares algorithm under several iterations solves the model parameters, and error is minimized in the least squares sense by solving the following equation.

$$
D=G M
$$

where $M$ is the model parameter matrix, $G$ the sensitivity matrix and $D$ is the data matrix.

$$
M=\left[\ln \Pi_{0}, \Delta f_{\mathrm{c}}\right]^{T}, G=\left[1,2 B_{4}^{-1} \frac{\left(f / f_{\mathrm{c}}\right)^{4}}{f_{\mathrm{c}}}\right]
$$

and

$$
D=\left[A(f)+0.5 \ln B_{4}\right] .
$$


Newton's method for quasi-linear equation yields

$$
\Delta M=\left(G^{T} G\right)^{-1} G^{T} \Delta D,
$$

where $\Delta M$ is the change in model parameters and $\Delta D$ is the difference between predicted and observed data. The solution is found iteratively using $M_{\mathrm{k}}=M_{0}+\Delta M_{k-1}$ where $M_{0}$ is the initial model. Since the sensitivity matrix is near to singular here, we use the Marquart-Lavenberg inversion technique to compute $\ln \Pi_{0}$ and $\Delta f_{\mathrm{c}}$ with ten iterations. Using the Marquart-Lavenberg inversion technique, eq. (8) it can be written as

$$
\Delta M=\left(G^{T} G+\lambda I\right)^{-1} G^{T} \Delta D,
$$

where $\lambda$ is the Levenberg-Marquardt adjustable damping parameter and $I$ is the identity matrix. The LevenbergMarquardt method was selected because: (i) it combines beneficial aspects of Gauss-Newton and gradient methods to avoid some of their weaknesses, (ii) the solution converges quickly, and (iii) a standard guess works well in many cases. In this study, $\lambda$ valued varied from 100 to 130 .

\section{Estimation of source parameters}

The source parameters such as seismic moment, source radius and stress drop were computed using the following equations after obtaining requisite model parameters from the above-discussed inversion technique ${ }^{14}$.

$$
\begin{aligned}
& \text { Seismic moment }\left(M_{0}\right)=\frac{4 \pi \rho V_{\mathrm{S}}^{3} R \Pi_{0}}{F R_{\theta \varphi}}, \\
& \text { Source radius }(r)=\frac{2.34 \times V_{\mathrm{S}}}{2 \pi f_{\mathrm{c}}}, \\
& \text { Sress drop }(\Delta \sigma)=\frac{7}{16} \frac{M_{0}}{r^{3}} \times 10^{-6}
\end{aligned}
$$

where $V_{\mathrm{S}}$ and $\rho$ are the $S$-wave velocity $(\mathrm{m} / \mathrm{s})$ and rock density $\left(\mathrm{kg} / \mathrm{m}^{3}\right)$ at the source. Rock density $\rho$ is computed from $V_{\mathrm{P}}\left(\rho=0.32 V_{\mathrm{P}}+0.77\right)^{31}$, where $V_{\mathrm{P}}$ is the $P$-wave velocity $(\mathrm{m} / \mathrm{s})$. It is important to have a fair knowledge of velocity structure in the study area for waveform analysis. The velocity structure of the study area similar to Bastar craton ${ }^{32}$ was used for the present calculation (cf. table 2 in Kayal et al. ${ }^{33}$ ). $\Omega_{0}$ represents the lowfrequency amplitude of the spectrum and $R$ denotes the hypocentral distance of the station $(\mathrm{m}) . F$ represents the free surface amplification factor, which is assumed to be 2 . The radiation factor $\left(R_{\theta \varphi}\right)$ is considered to be 0.55 for the present study region. Moment magnitude is computed using the equation as given below ${ }^{34}$

$$
M_{\mathrm{w}}=\frac{2}{3} \log _{10}\left(M_{0}\right)-6.06 \text {. }
$$

The source displacement $(d)$ or average source dislocation, directly proportional to the seismic moment $\left(M_{0}\right)$ and inversely proportional to the rigidity $(\mu)$ of the source material $^{35}$ and area $(A)$ of the circular rupture plane, is computed using the following equation.

$$
d=\frac{M_{0}}{\mu A},
$$

where $\mu=V_{\mathrm{S}}^{2} \rho$ and $A=\pi r^{2}$.

The radiated energy $\left(E_{\mathrm{S}}\right)$, according to the model of Orowan $^{36}$, is computed using the following relationship.

$$
E_{\mathrm{S}}(\mathrm{J})=\frac{M_{0} \Delta \sigma}{2 \mu}
$$

\section{Results}

Source parameters such as corner frequency $\left(f_{\mathrm{c}}\right)$, seismic moment $\left(M_{0}\right)$, stress drop $(\Delta \sigma)$, source radius $(r)$, source displacement $(d)$, moment magnitude $\left(M_{\mathrm{w}}\right)$ and radiated energy $\left(E_{\mathrm{S}}\right)$ were computed based on waveform analysis of 17 local crustal earthquakes recorded at IIT(ISM) digital broadband station. The earthquake catalogue of IMD was used to compile the hypocentral parameters of these 17 events (Table 1). It was found that most of the events were distributed sporadically over the Eastern Indian Shield region. Source parameters of nine local crustal events (Table 1, Figure 1) were compiled and jointly analysed with the computed parameters of the 17 events for a better understanding of seismogenesis of the Eastern Indian Shield region ${ }^{17}$. We found the values of corner frequency to vary from 4.56 to $8.62 \mathrm{~Hz}$, seismic moment from $6.2 \mathrm{E}+12$ to $2.11 \mathrm{E}+16 \mathrm{~N}-\mathrm{m}$, stress drop from 0.11 to $37.13 \mathrm{MPa}$, source radius from 144 to $291 \mathrm{~m}$, source displacement from 0.24 to $229 \mathrm{~cm}$, moment magnitude from 2.44 to 4.82 , and radiated seismic energy from $8.3 \mathrm{E}+06$ to $1.13 \mathrm{E}+13 \mathrm{~J}$.

Regression analysis among the various source parameters for the 26 events was carried out using least square regression analysis. The following empirical relationships have been established for understanding the mutual dependency of seismic moment, radiated seismic energy, source radius, stress drop and source displacement (Figure 4).

$$
\begin{aligned}
& \log \left(E_{\mathrm{s}}\right)=1.68 \log \left(M_{0}\right)-14.5, \\
& \log (r)=0.08 \log \left(M_{0}\right)+1.13, \\
& \log (\Delta \sigma)=0.75 \log \left(M_{0}\right)-10.67, \\
& \log (d)=0.84 \log \left(M_{0}\right)-13.26,
\end{aligned}
$$



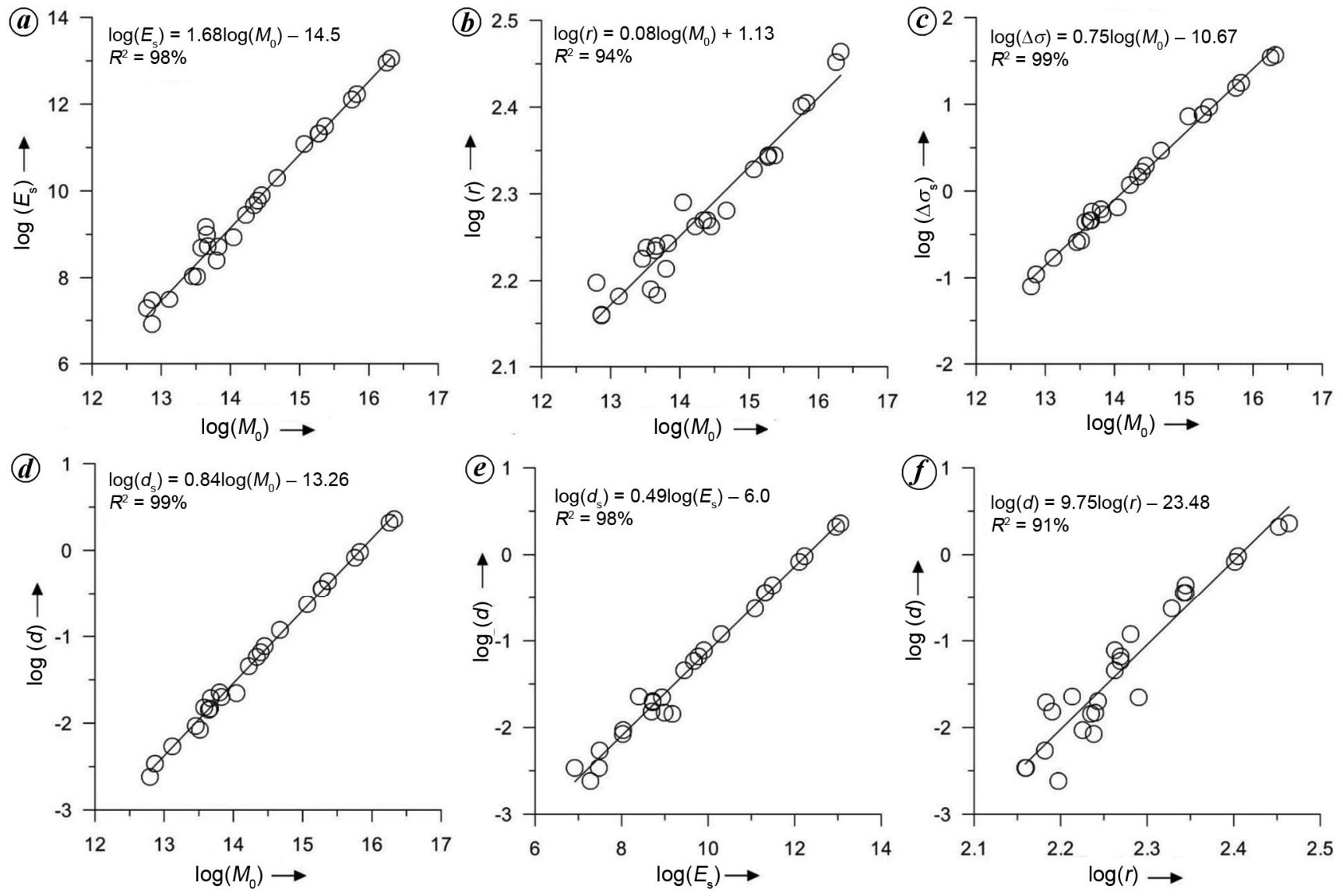

Figure $4 \boldsymbol{a}-\boldsymbol{f}$. Empirical relationships between different source parameters.

$$
\begin{aligned}
& \log (d)=0.49 \log \left(E_{\mathrm{s}}\right)-6.0 \\
& \log (d)=9.75 \log (r)-23.48
\end{aligned}
$$

The present study also establishes the following empirical relationships between moment magnitude, seismic moment, source radius, stress drop and corner frequency (Figure 5).

$$
\begin{aligned}
& \log \left(M_{0}\right)=1.48 M_{\mathrm{w}}+9.18, \\
& \log (r)=0.12 M_{\mathrm{w}}+1.86, \\
& \log (\Delta \sigma)=1.12 M_{\mathrm{w}}-3.74 .
\end{aligned}
$$

Empirical relationships between slip, fault dimension and seismic moment for earthquakes that occur in a tectonic domain are closely tied with their magnitudes. The radiated seismic waves were used for estimating the stress drop associated with faulting. It was found from seismological observations that the best-constrained quantity is the seismic moment ${ }^{37}$ and that stress drop can be estimated from the knowledge of fault dimension. For the circular fault model ${ }^{14}$, the estimated corner frequency from a spectrum of the seismic wave can give the fault dimension, and hence the value of stress drop using eqs (10)-(12). So, stress drop is difficult to measure precisely and the estimated values of $\Delta \sigma$ exhibit a great deal of scatter ${ }^{38}$. Although positive correlations between seismic moment, radiated seismic energy, source displacement were obtained in the present study (eqs (16)-(21)), a probable relationship was found between stress drop and seismic moment with $R^{2}$ value of $99 \%$ (Figure $4 c$ ). A similar correlation with $R^{2}$ value of $99 \%$ was also found for moment magnitude and stress drop (Figure $5 \mathrm{c}$ ). This breakdown in self-similarity below a threshold moment of $<4.73 \mathrm{E}+14 \mathrm{~N}-\mathrm{m}$ for smaller events with moment magnitude $<3.72$, possibly resulted from continuous rupturing over a fault plane in the study area ${ }^{39}$. Similar breakdown was also noted by others for earthquakes that occurred elsewhere around the globe ${ }^{40-44}$. The size-dependent stress drop for smaller magnitude events was also identified by Mandal and Jhonston ${ }^{45}$ for Bhuj area, India. The variable stress drop values, that have positive correlation with either seismic moment or magnitude of events, might indicate that rock masses constituting the crust in the region are of widely variable strength. Laboratory experiments indicate that stress drop during fracturing of rocks is less than its strength. It is unclear 

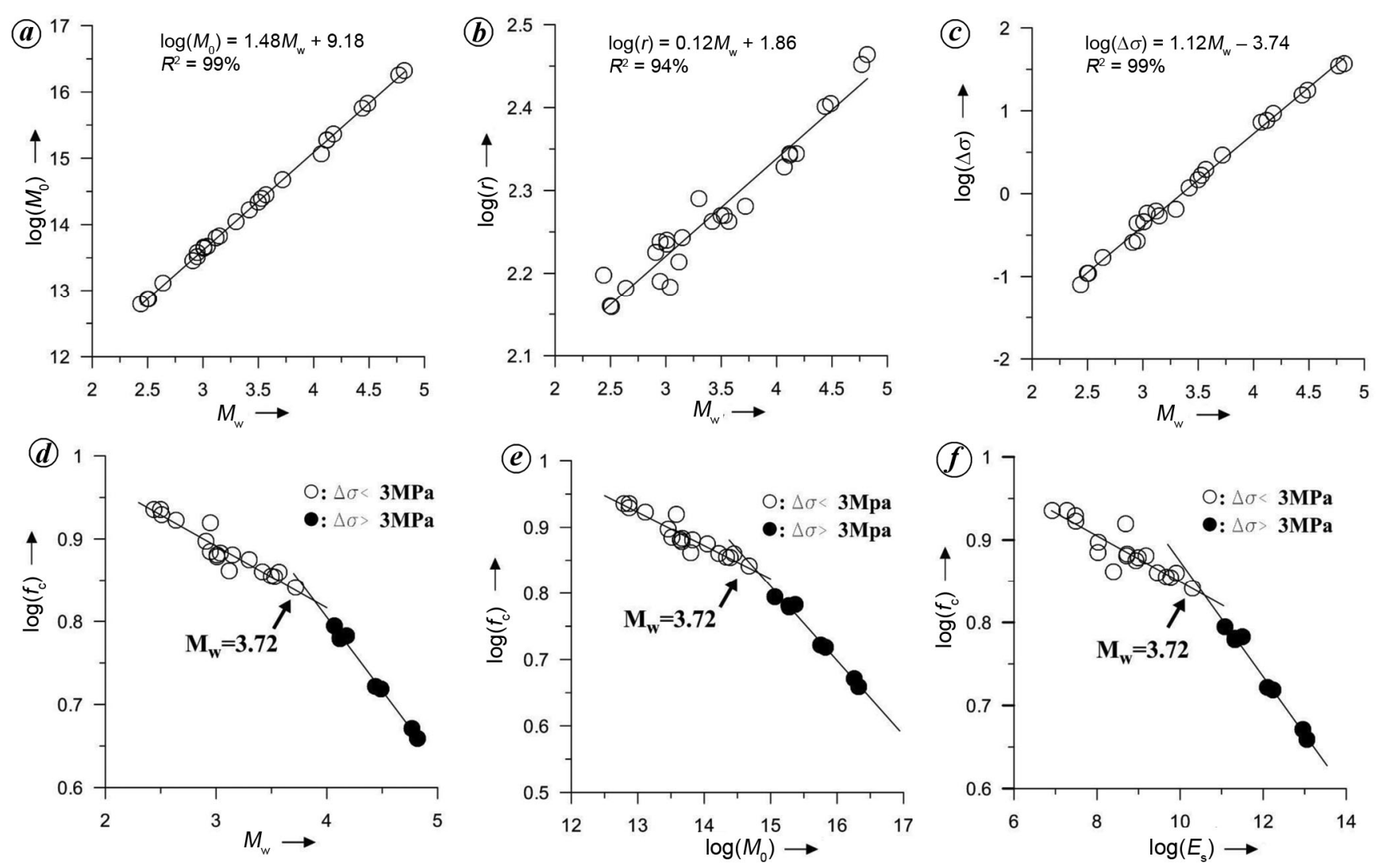

Figure $5 \boldsymbol{a}-\boldsymbol{f}$. Empirical relationships between different source parameters.

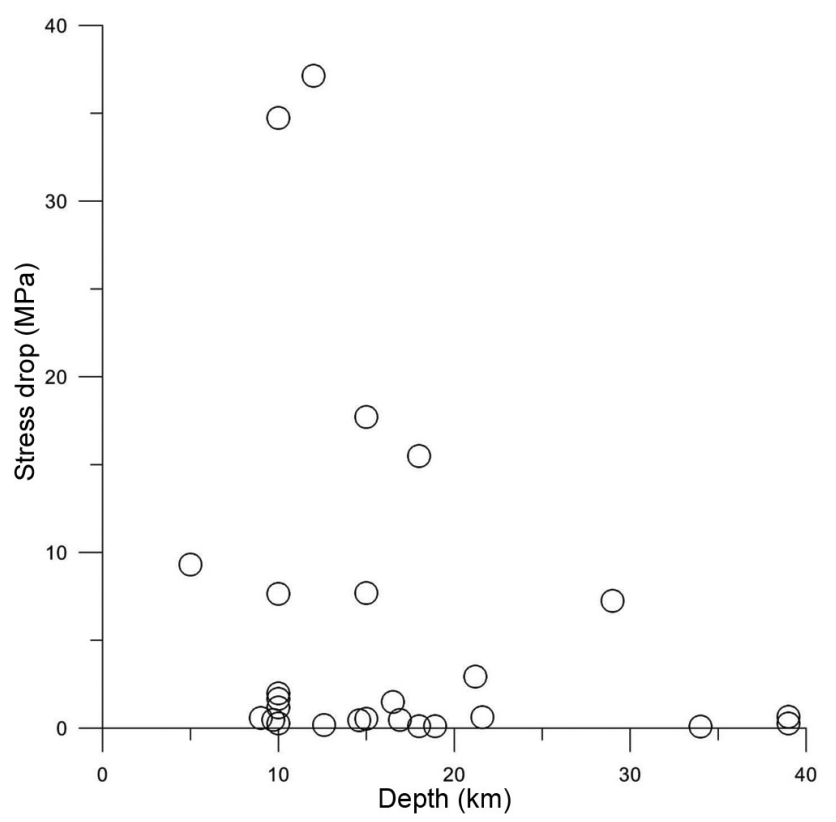

Figure 6. Variation in stress drop of 26 local crustal earthquakes with respect to their focal depths.

how the released energy or magnitude of an earthquake is correlated with the elapsed time of the faulting process or perhaps stress drop under different tectonic environments. Low stress drop sometimes results from interrupted rupturing on an existing fault plane ${ }^{46}$. Figure 6 illustrates the variation of stress drop of events with respect to their focal depths. No correlation is apparently found between these parameters; instead a high stress drop associated with shallow earthquakes $(\sim 10 \mathrm{~km}$ focal depth, Figure 6) is observed (Table 1). Very low stress drop is also found at deeper levels of the crust. This observation accounts for heterogeneities present in the crustal part beneath the study area.

It was also found that the relationships between seismic moment, source radius, source displacement, moment magnitude, corner frequency and radiated seismic energy (Figures $4 b, f$ and $5 b, d-f$ ) were different for stress drop intervals: $\Delta \sigma>3.0 \mathrm{MPa}$ and $\Delta \sigma<3.0 \mathrm{MPa}$. Source dimension and source displacement were closely related with corner frequency, and hence stress drop (eqs (11)(12)). Thus, the above correlations over different stress intervals might indicate the failure of rock masses under strain weakening at low deviatoric stress ${ }^{44}$, and brittle failure in less competent subsurface medium.

\section{Discussion and conclusion}

Positive correlation of radiated seismic energy, source radius, stress drop, source displacement against seismic moments (Figure $4 a-d$ ), and source displacement against radiated energy and source radius (Figure $4 e$ and $f$ ) have been established for the Eastern Indian Shield and 
adjacent regions. Further, a positive correlation of seismic moment, source radius and stress drop against moment magnitude has also been established for the region (Figure $5 a-c$ ). In addition, a negative correlation is observed for corner frequency against moment magnitude, seismic moment and radiated seismic energy (Figure $5 d-$ $f$ ). However, the decrease in corner frequency is different at stress drop $>3.0$ and $<3.0 \mathrm{MPa}$. These correlations over different stress drop intervals apparently result from faulting processes and associated rupture propagation under varying heterogeneities. It was found that the depths of 20 events are very shallow $(<20 \mathrm{~km})$, associated with the upper crust, likely caused by reactivation processes in the basement. In contrast, two events were identified in the deeper parts of the crust (focal depth $39 \mathrm{~km}$ ), while three events were associated with the boundary between the lower and upper crust. Although these local events have some depth uncertainty, the recording stations are located within the study area, thus reducing the depth error within the expected limits (as discussed before). Further, only two events of depth of $39 \mathrm{~km}$ occurred near the Moho, and other events lay well within the crust, particularly in the upper crust. However, deformation in the more homogeneous deeper parts in this area was also apparently active, and further research using more earthquake data is required for an in-depth understanding of these processes. Fault reactivation induced by reactive fluids causes rock failure and triggers small-magnitude earthquakes, and presumably occurs in the shallower part of the crust. Kirby ${ }^{47}$ reported that strain localization is an important phenomenon in rocks metamorphosed under middle to shallow crustal conditions in the intraplate region. Four major factors, viz. lithostatic pressure, state of stress (depends on orientation of $\sigma_{1}$ and $\sigma_{3}, \sigma_{1}$ : maximum principal compressive stress, $\sigma_{3}$ : minimum principal compressive stress), fluid pressure ${ }^{48}$, chemical effects of reactive fluids ${ }^{49}$ cause the failure of rocks in the crust. Further, the relevant rock-failure processes are sometimes thermally activated, and ductile strengths are reduced with increasing temperatures, and straining to weaken results in less stress drop during rupturing ${ }^{50}$.

Several observations also suggest that large deformations of the continental lithosphere, such as at the plate boundaries, are accommodated largely by localized deformation along ductile shear zones as well as along brittle faults or heterogeneities. Laboratory observations show that accumulation of strain into the shear zones initiates faulting, and the faulting process may be initiated by the onset of dynamic recrystallization, phase changes, hydrothermal alteration and hydrolytic weakening ${ }^{51}$. This raises the possibility that strain softening and localization may control stress differences in the continental crustal processes close to near-surface faulting, and shallowlevel seismicity is obvious as brittle manifestations of strain localization in the upper continental crust. Presence of several hot springs in the study region (Figure 1) and passing of the crest of flexural bulging of the Indian plate through this region ${ }^{52,53}$, might indicate a high thermal regime at shallow level either due to shallow heat source or upliftment of Moho, or both ${ }^{54,55}$. Thus, ductile strain localization in the shear zones or reactivation of fractures in the presence of high thermal regime cannot be ruled out. It may thus be proposed that strain localization and brittle failure occurring in the zones of rich silicate layers produced by hydrothermal alteration ${ }^{56}$ are common tectonic features in this part of the Eastern Indian Shield.

1. Ansari, M. A. and Khan, P. K., Occurrences of damaging earthquakes between the Himachal and Darjeeling Himalayas: tectonic implications. Acta Geophys., 2014, 62, 699-736.

2. Khan, P. K., Ansari, A. and Singh, D., Insights into the great $M_{\mathrm{w}}$ 7.9 25 April 2015 Nepal earthquake. Curr. Sci., 2017, 113, 2014 2020.

3. Chandra, U., Earthquakes of Peninsular India - a seismotectonic study. Bull. Seismol. Soc. Am., 1977, 67, 1387-1413.

4. Bapat, A., Kulkarni, R. C. and Guha, S. K., Catalogue of Earthquakes in India and neighbourhood from historical period up to 1979. Indian Society of Earthquake Technology, Roorkee, India, 1983.

5. Talwani, P., Fault geometry and earthquakes in continental interiors. Tectonophysics, 1999, 305, 371-379.

6. Mishra, O. P. and Zhao, D., Crack density, saturation rate and porosity at the 2001 Bhuj, India, earthquake hypocenter: a fluiddriven earthquake. Earth Planet. Sci. Lett., 2003, 212, 393-405.

7. Mandal, P., Rastogi, B. K., Satyanarayana, H. V. S. and Kousalya, M., Results from local earthquake velocity tomography: implications toward the source process involved in generating the 2001 Bhuj earthquake in the lower crust beneath Kachchh (India). Bull. Seismol. Soc. Am., 2004, 94, 633-649.

8. Schulte, S. M. and Mooney, W. D., An updated global earthquake catalogue for stable continental regions: reassessing the correlation with ancient rifts. Geophys. J. Int., 2005, 161, 707-721.

9. Khan, P. K., Mohanty, S. P., Sinha, S. and Singh, S., Occurrences of large-magnitude earthquakes in the Kachchh region, Gujarat, western India: tectonic implications. Tectonophysics, 2016, 679, 102-116.

10. Bodin, P. and Horton, S., Source parameters and tectonic implications of aftershocks of the $M_{\mathrm{w}}$ Bhuj earthquake of 26 January 2001. Bull. Seismol. Soc. Am., 2004, 94, 818-827.

11. Allmann, B. P. and Shearer, P. M., Global variations of stress drop for moderate to large earthquakes. J. Geophys. Res., 2009, 114(B01310), 1-22.

12. Chung, W. Y. and Kanamori, H., Variation of seismic source parameters and stress drops within a descending slab and its implications in plate mechanics. Phys. Earth Planet. Inter., 1980, 23, 134-159.

13. Jain, R., Rastogi, B. K. and Sharma, C. S. P., Precursory changes in source parameters for the Koyna-Warna (India) earthquakes. Geophys. J. Int., 2004, 158, 915-921.

14. Brune, J. N., Tectonic stress and spectra of seismic shear waves. J. Geophys. Res., 1970, 75, 4997-5009.

15. Srivastav, S. K., Prakash, R., Dattatrayam, R. S., Arora, S. K., Bansal, B. K. and Bhattacharya, S. N., Configuration of an optimum seismological network for India. Mausam, 2005, 56, 465-472.

16. Prakash, R., Suresh, G. and Gahalaut, V. K., Earthquake monitoring in India. Proc. Indian Natl. Sci. Acad., 2020, 86, 631-642.

17. Biswas, B. and Mandal, P., Modeling of source parameters and moment tensors of local earthquakes occurring in the Eastern Indian Shield. J. Geol. Soc. India, 2017, 89, 619-930.

18. Bose, M. K., Precambrian mafic magmatism in the Singhbhum Craton, Eastern India. J. Geol. Soc. India, 2009, 73, 13-35. 


\section{RESEARCH ARTICLES}

19. Sarkar, A. N., Precambrian tectonic evolution of eastern India: a model of converging microplates. Tectonophysics, 1982, 86, 363 397.

20. Khan, P. K., Variation in dip angle of the Indian plate subducting beneath the Burma plate and its tectonic implications. Geosci. J., 2005, 9, 227-234.

21. Khan, P. K. and Chakraborty, P. P., The seismic $b$ value and its correlation with Bouguer gravity anomaly over the Shillong plateau area: a new insight for tectonic implication. J. Asian Earth Sci., 2007, 29, 136-147.

22. Khan, P. K., Shamim, Sk., Mohanty, S. P. and Aggarwal, S. K., Change of stress patterns during $2004 M_{\mathrm{w}} 9.3$ off-Sumatra mega-event: insights from ridge-trench interaction for plate margin deformation. Geol. J., 2020, 55, 372-389.

23. Weissel, J. K., Anderson, R. N. and Geller, C. A., Deformation of the Indo-Australian plate. Nature, 1980, 287, 284-291.

24. Shamim, S. K., Khan, P. K. and Mohanty, S. P., Stress reconstruction and lithosphere dynamics along the Sumatra subduction margin. J. Asian Earth Sci., 2019, 170, 174-187.

25. Bose, M. K., Petrology and geochemistry of Proterozoic 'newer Dolerite' and associated ultramafic dykes within Singhbhum granite pluton, eastern India. In Indian Dykes: Geochemistry, Geophysics, and Geochronology (eds Srivastava, R. K., Sivaji, C. and Chalapathi Rao, N. V.), Narosa Publishing House Pvt Ltd, New Delhi, 2008, pp. 413-445.

26. Pandey, O. P. and Agrawal, P. K., Lithospheric Mantle Deformation beneath the Indian cratons. J. Geol., 1999, 107, 683-692.

27. Sarkar, S. N. and Saha, A. K., Present status of the Precambrian stratigraphy, tectonics and geochronology of Singhbhum, Keonjhar, Mayurbhanj region, eastern India, Indian. J. Earth. Sci., 1977, 4, 37-55.

28. Boatwrlght, J., A spectral theory for circular seismic sources, rumple estimates of source dimension, dynamic stress drop, and radiated energy. Bull. Seismol. Soc. Am., 1980, 70, 1-28.

29. Fletcher, J. B., Source parameters and crustal $Q$ for four earthquakes in South Carolina. Seismol. Res. Lett., 1995, 66, 44-58.

30. Press, W. H., Teukolsky, S. A., Vetterling, W. T. and Flannery, B. P., Numeric Recipes in C: the Art of Scientific Computing, Cambridge University Press, New York, USA, 1992, 2nd edn, p. 345.

31. Berteusen, K. A., Moho depth determinations based on spectral ratio analysis of NORSAR long-period P-waves. Phys. Earth Planet. Inter., 1977, 31, 313-326.

32. Bhattacharya, S. N., Suresh, G. and Mitra, S., Lithospheric $S$-wave velocity structure of the Bastar craton, Indian Peninsula, from surface-wave phase velocity measurements. Bull. Seismol. Soc. Am., 2009, 99, 2502-2508.

33. Kayal, J. R., Srivastava, V. K., Bhattacharya, S. N., Khan, P. K. and Chatterjee, R., Source parameters and focal mechanisms of local earthquakes: single broadband observatory at ISM Dhanbad. J. Geol. Soc. India, 2009, 4, 413-419.

34. Hanks, T. C. and Kanamori, H., A moment-magnitude scale. J. Geophs. Res., 1979, 84, 2348-2350.

35. Aki, K., Generation and propagation of $G$-waves from the Niigata earthquake of 16 June 1964. Estimation of earthquake moment, released energy, and stress-strain drop from the $G$-wave spectrum. Bull. Earthquake Res. Inst., Univ. Tokyo, 1966, 44, 73-88.

36. Orowan, E., Mechanism of seismic faulting. Geol. Soc. Am. Memoir, 1960, 79, 323-345.

37. Stein, S. and Wysession, M., An Introduction to Seismology, Earthquakes, and Earth Structure, Blackwell Publishing Ltd, UK, 2008, p. 498.

38. Shearer, P. M., Introduction to Seismology, Cambridge University Press, UK, 1999, p. 260.

39. Scholz, C. H., The Mechanics of Earthquakes and Faulting, Cambridge University Press, New York, USA, 1990, p. 441.
40. Rautian, T. G. and Khalturin, V. I., The use of the coda for determination of the earthquake source spectrum. Bull. Seismol. Soc. Am., 1978, 68, 923-948.

41. Hasegwa, H. S., Lg spectra of local earthquakes recorded by the Eastern Canada Telemetered Network and spectral scaling. Bull. Seismol. Soc. Am., 1983, 75, 1569-1581.

42. Harr, L. C., Fletcher, J. B. and Mueller, C. S., The 1982 Enola, Arkansas, swarm and scaling of ground motion in the eastern United States. Bull. Seismol. Soc. Am., 1984, 74, 2463-2482.

43. Mandal, P. and Dutta, U., Estimation of earthquake source parameters in the Kachchh seismic zone, Gujarat, India, from strongmotion network data, using a generalized inversion technique. Bull. Seismol. Soc. Am., 2011, 101, 1719-1731.

44. Bora, D. K., Baruah, S., Biswas, R. and Gogoi, N. K., Estimation of source parameters of local earthquakes originated in ShillongMikir Plateau and its adjoining region of northeast India. Bull. Seismol. Soc. Am., 2013, 103, 437-446.

45. Mandal, P. and Jhonston, A., Estimation of source parameters for the aftershocks of the $2001 M_{\mathrm{w}}$ Bhuj earthquake, India. Pure Appl. Geophys., 2006, 163, 1537-1560.

46. Upadhayay, S. K. and Ahuja, V. K., Source parameters of earthquakes in northeast India from spectra of Rayleigh waves. Tectonophysics, 1981, 75, 297-315.

47. Kirby, S. H., Rock mechanics observations pertinent to the rheology of the continental lithosphere and the localization of strain along shear zones. Tectonophysics, 1985, 119, 1-27.

48. Brace, W. F. and Kohlstedt, D. L., Limits on lithospheric stress imposed by laboratory experiments. J. Geophys. Res., 1980, 85, $6248-6252$.

49. Kirby, S. H., Introduction and digest to the special issue on chemical effects of water on the deformation and strengths of rocks. J. Geophys. Res., 1984, 89, 3991-4358.

50. Paterson, M. S., Experimental Rock Deformation-The Brittle Field, Springer, Berlin, Germany, 1978, p. 252.

51. Kirby, S. H., Rheology of the lithosphere. Rev. Geophys. Space Phys., 1983, 21, 1458-1487.

52. Bilham, R., Bendick, R. and Wallace, K., Flexure of the Indian plate and intraplate earthquakes. Proc. Indian Acad. Sci., 2003, 112, 315-329.

53. Khan, P. K., Bhukta, K. and Tarafder, G., Coda Q in Eastern Indian Shield. Acta Geoda. Geophys., 2016, 51, 333-346.

54. Rao, R. U. M., Rao, G. V. and Narain, H., Radioactive heat generation and heat flow in the Indian Shield. Earth Planet. Sci. Lett., 1976, 30, 57-64.

55. Rao, G. V. and Rao, R. U. M., Heat flow in Indian Gondwana basins and heat production of their basement rocks. Tectonophysics, 1983, 91, 105-117.

56. Segall, P. and Pollard, D. D., Joint formation in the granitic rock of the Sierra Nevada. Geol. Soc. Am. Bull., 1983, 94, 563-575.

57. Dasgupta, S. et al., Seismotectonic Atlas of India and its Environs (eds Narula, P. L., Acharya, S. K. and Banerjee, J.), 2000, p. 87.

ACKNOWLEDGEMENTS. We thank the Director, Indian Institute of Technology (Indian School of Mines; IIT(ISM)), Dhanbad for providing the necessary facilities, and Shri Raj Kumar Prasad (Senior Technical Assistant) for providing the earthquake data recorded at the IIT(ISM) Broadband station. The study was funded by the Ministry of Earth Sciences, Government of India. We also thank the two anonymous reviewers for useful suggestions that helped improve the manuscript.

Received 29 May 2019; revised accepted 27 June 2020

doi: $10.18520 / \mathrm{cs} / \mathrm{v} 119 / \mathrm{i} 7 / 1159-1168$ 